\title{
HABILIDADES E COMPETÊNCIAS DO ADMINISTRADOR DESENVOLVIDAS POR MEIO DA ELABORAÇÃO DO TCC
}

CURITIBA/PR MAIO/2018

\author{
ELAINE CRISTINA HOBMEIR - UNINTER - elaine.h@uninter.com \\ ADEMIR MOREIRA BUENO - UNINTER - ademir.b@uninter.com \\ ALINE MARA GUMZ EBERSPACHER - UNINTER - aline.e@uninter.com
}

\author{
Tipo: Relato de Experiência Inovadora (EI) \\ Categoria: Conteúdos e Habilidades \\ Setor Educacional: EDUCAÇÃO SUPERIOR
}

\begin{abstract}
RESUMO
Este artigo tem por objetivo analisar as competências do graduando na realização do TCC no curso de Administração modalidade EAD de uma Instituição de Ensino Superior localizada na cidade de Curitiba. Para tanto, se buscou conhecer a partir da análise das Diretrizes Curriculares Nacionais $D C N$, do Exame Nacional de Desempenho de Estudantes - ENADE e do Conselho Federal de Administração - CFA, quais são as competências exigidas do egresso. Para essa análise partiu-se da proposta do TCC do curso. O objetivo da pesquisa é verificar se as competências definidas nas DCN, contempladas no PPC e formuladas nos Planos de Ensino - do currículo do Curso de Graduação em Administração - estão de fato sendo contemplados nos objetivos do Trabalho de Conclusão de Curso e se estes conseguem contribuir para formar o perfil esperado do egresso. Em nosso percurso metodológico, optamos por uma pesquisa bibliográfica e estudo descritivo no sentido da análise dos pontos de discussão para as características do assunto abordado, realizado através de seus componentes na intenção de avaliá-los.
\end{abstract}

Palavras-chave: Competências; Interdisciplinaridade; Aprendizagem; 


\section{INTRODUÇÃO}

Cada dia mais a EaD cresce exponencialmente no Brasil. Novas instituições investem nesta modalidade, as que já estão a mais tempo no mercado contratam novos colaboradores. Os candidatos a cursos superiores veem nesta forma de educação uma possibilidade de enfim ter um diploma de curso superior de forma mais acessível e com isto acrescentar uma gama de novos conhecimentos, habilidades e competências às suas carreiras. Dentro do contexto acadêmico, a gestão por competências é essencial para qualquer curso, isso não poderia ser diferente para o curso de Administração, principalmente quando se está formando gestores. Sob este prisma foi criado o novo conceito de TCC, tornando possível testar se as competências exigidas para um administrador são formadas por meio das disciplinas do curso, especialmente através do Trabalho de Conclusão de Curso - TCC. Esse artigo está organizado da seguinte forma: a introdução, uma discussão breve sobre os aspectos teóricos do EAD, e na sequencia apresentamos as competências esperadas do Administrador. Logo depois, descrevemos como o TCC I e II estão organizados, em seguida, fazemos a comparação entre o que se espera em termos de formação relacionando competências e o que o TCC propicia em termos de desenvolvimento. Para finalizar estão as considerações finais e as referências.

\section{UMA ABORDAGEM HISTÓRICA E CONSTITUTIVA DA EAD}

A ideia principal da EaD está centrada na diferença básica entre a localização de estudantes e professores, uma vez que os mesmos, durante todo ou grande parte do tempo em que aprendem e ensinam, encontram-se em locais distintos, e dependem de algum tipo de tecnologia para a interação entre eles (MOORE; KEARSLEY, 2008). Nesta modalidade, não importa o lugar onde o estudante esteja, ele tem acesso ao conhecimento que está disponível nas redes. Assim, as tecnologias viabilizam o aparecimento das escolas virtuais, modalidade de EaD para todos os assuntos e níveis (KENSKI, 2012). No caso dos estudos que ocorrem pela internet é comum que os estudantes acessem o curso em diferentes locais, utilizando os materiais e recursos didáticos em momentos diferentes. Segundo a visão de Moore e Kearsley (2008, p. 2): EaD é o aprendizado planejado que ocorre normalmente em um lugar diferente do local do ensino, exigindo técnicas especiais de criação do curso e de instrução, comunicação por meio de várias tecnologias e disposições organizacionais e administrativas especiais. Aos poucos, as dúvidas com relação à credibilidade do EaD estão sendo deixadas para trás, como está registrado no Relatório Analítico da Aprendizagem a Distância no Brasil de 2010, realizado pela Associação Brasileira de EaD (ABED). A EaD já foi considerada, no Brasil, uma educação de menor qualidade, destinada aos 
que, por questões socioeconômicas, não tinham acesso ao ensino formal. Assim, eram desenvolvidos cursos que ensinavam, entre outros assuntos, conteúdos de corte e costura taquigrafia, montagem e conserto de rádios e televisores. Hoje, a situação encontra-se bem diferente. Há uma legislação que apoia a formação a distância e a certificação do aluno dos cursos de EAD autorizados passou a ter o mesmo valor que os cursos presenciais. (ABED, Relatório Analítico, 2010). Um dos cursos que possui mais estudantes na modalidade EaD é Administração, pois possibilita uma formação ampla, dando ao acadêmico uma gama de possibilidades de atuação, esse é um dos motivos de ser um dos cursos mais procurados. As IES têm a liberdade de ofertar, ou não, o TCC - Trabalho de Conclusão de Curso em sua grade de disciplinas. As que o fazem, sabem das implicações desta decisão, desde o gerenciamento de todo o processo até a apresentação dos trabalhos e avaliação para aprovação ou não por banca examinadora. Neste artigo, analisaremos como a estrutura e funcionamento do TCC que compõe a grade do curso de Administração de uma IES instalada na cidade de Curitiba pode contribuir e em que grau para a formação das habilidades e competências exigidas do Administrador. Em nosso percurso metodológico, optamos por um estudo descritivo no sentido de pontos de discussão para as características do assunto abordado, realizado através de seus componentes na intenção de avaliá-los (GIL, 2009). O levantamento bibliográfico se baseou, entre outros autores, nas competências esperadas nas DCN, no ENADE e nas estabelecidas pelo CFA. Foi realizada uma análise das competências dos referidos órgãos e relacionados com o TCC ofertado pelo curso de Administração.

\section{COMPETÊNCIAS DO ADMINISTRADOR}

Em todos os cursos de nível superior o PPC - Projeto Pedagógico do Curso descreve entre outras coisas as habilidades e competências que se espera que o egresso tenha ao finalizar seu curso superior, a base para a IES elaborar essas competências e habilidades são as DCNs - Diretrizes Curriculares Nacional, elaboradas pelo MEC e devem ser a fonte para que se faça a estrutura do curso pela IES. O grande desafio para a instância pública que elabora as DCNs e as IES que descrevem seus PPCs é unir o que é apresentado pelo MEC e aquilo que o mercado de trabalho espera de profissionais formados em cursos superiores. O alinhamento destas instâncias é um desafio aos Coordenadores de cursos, área pedagógica e professores, os quais em última instância é que aplicam o que foi projetado para os cursos onde ministram aulas. Diante da exposição de que, as bases que são utilizadas para definição do perfil do egresso, o problema da pesquisa deste artigo está voltado a conhecer se: as competências definidas nas DCN, contempladas no PPC e formuladas nos PE - do currículo do Curso de Graduação em Administração - estão de fato sendo contemplados nos objetivos do Trabalho de Conclusão de Curso e se estes 
conseguem contribuir para formar o perfil esperado do egresso? Nos interessa saber, ao fim deste, como os TCC I e II do curso de Administração de uma IES instalada em Curitiba contribuem na formação das competências previstas nas DCN, e como isso se viabiliza na prática. O objetivo é verificar se as atividades solicitadas nos TCCs I e II, das atividades solicitadas contribui em qual nível para a formação das habilidades e competências esperadas dos egressos. Com o objetivo de elucidar essas habilidades, será descrito abaixo as competências esperadas da DCN, do ENADE e do CFA.

Competências esperadas do egresso segundo as DCN: I - reconhecer e definir problemas, equacionar soluções, pensar estrategicamente, introduzir modificações no processo produtivo, atuar preventivamente, transferir e generalizar conhecimento e exercer, em diferentes graus de complexidade, o processo de tomada de decisão; II desenvolver expressão e comunicação compatíveis com o exercício profissional, inclusive nos processos de negociação e nas comunicações interpessoais ou intergrupais; III - refletir e atuar criticamente sobre a esfera da produção, compreendendo sua posição e função da estrutura produtiva sob seu controle e gerenciamento; IV - desenvolver raciocínio lógico, crítico e analítico para operar com valores e formulações matemáticas presentes nas relações formais e causais entre fenômenos produtivos, administrativos e de controle, bem assim expressando-se de modo crítico e criativo diante dos diferentes contextos organizacionais e sociais; $\mathrm{V}$ - ter iniciativa, criatividade, determinação, vontade política e administrativa, vontade de aprender, abertura às mudanças e consciência de qualidade e das implicações éticas do seu exercício profissional; VI - desenvolver capacidade de transferir conhecimentos da vida e da experiência cotidiana para o ambiente de trabalho e do seu campo de atuação, em diferentes modelos organizacionais, revelando-se profissional adaptável; VII desenvolver capacidade de elaborar, implementar e consolidar projetos em organizações e; VIII - desenvolver capacidade para realizar consultoria em gestão e administração, pareceres e perícias administrativas, gerenciais, organizacionais, estratégicos e operacionais (BRASIL, 2005)

Competências exigidas através ENADE: A Portaria do Inep no 217 de 10 de junho de 2015 que foi publicada no Diário Oficial de 12 de junho de 2015, Seção 1, pág. 17Art. 6º descreve que a prova do Enade 2015, no componente específico da área de Administração, avaliará se o estudante desenvolveu, no processo de formação, as competências e habilidades para: I - Reconhecer e delimitar problemas e oportunidades; II - Propor e implementar, com efetividade, ações alinhadas às estratégias da organização; III - Promover a comunicação no ambiente organizacional interno e externo; IV - Coordenar e integrar as diferentes áreas funcionais da organização; V Identificar e alocar recursos, pessoas e funções; VI - Desenvolver o capital humano, 
mediante liderança e trabalho em equipe; VII - Monitorar resultados e avaliar desempenho; VIII - Lidar com mudanças e situações de risco.

Competências do Administrador segundo o CFA: A seguir, as competências apresentadas pelo Sistema CFA/CRAs, fruto de pesquisa nacional realizada sobre o perfil do Administrador e do Tecnólogo, a qual teve por objetivo o desenvolvimento de ações estratégicas para a normatização, o aperfeiçoamento e a valorização da categoria profissional. As competências: I - Identificar problemas, formular e implantar soluções; II - Desenvolver raciocínio lógico, crítico e analítico sobre a realidade organizacional; III Assumir o processo decisório das ações de planejamento, organização, direção e controle; IV - Ser capaz de negociar, mediar e arbitrar conflitos; V - Elaborar e interpretar cenários.

\section{O TCC E ESTRUTURA DO TCC I e II}

Dependendo do Projeto Pedagógico do Curso (PPC) e das normativas da instituição, ao final do curso o aluno poderá precisar realizar um Trabalho de Conclusão de Curso (TCC), que tem como objetivo contribuir para a formação do Administrador, ao mesmo tempo permite a ele aplicar todos os conhecimentos adquiridos durante a trajetória do seu curso, nas diversas áreas de atuação. No TCC o aluno deve demonstrar a sua capacidade de inovar cientificamente. Segundo Severino (2007, p. 202) para a grande maioria dos alunos o TCC "representa a primeira experiência de realização de uma pesquisa" O importante é que neste caso o aluno construa o seu conhecimento e consolide a sua formação. Na instituição pesquisada o TCC é dividido em duas etapas (TCC I E TCC II), conforme descrito na sequência.

TCC I O acadêmico ao cursar a disciplina TCC I deverá elaborar a modelagem de um negócio a partir do BMG Canvas - Quadro do Modelo de Negócios, O Business Model Canvas que foi inicialmente proposto por Alexander Osterwalder (2011), trata-se de um formulário com nove campos a serem preenchidos, que são: as propostas de valor, os segmentos de clientes, o relacionamento com clientes, os canais, os parceiros chave, as atividades chave, os recursos chaves, a estrutura de custos e a fontes de receita. Para orientar o acadêmico EaD na execução do Canvas, foi elaborado um Manual tratando do detalhamento de cada campo do BMG Canvas, o qual ficará disponível para o acadêmico durante o período de realização do TCC. A partir da leitura, o acadêmico definirá qual negócio modelará, preencherá o formulário e a seguir descreverá detalhadamente cada um dos campos, apresentando fundamentação teórica com o conceito de cada um deles, suas características e preencherá tabelas com detalhamento de cada campo, com vistas a esmiuçar todos os pontos para facilitar a compreensão de 
cada aspecto do negócio escolhido. Ao finalizar, o acadêmico postará no AVA Ambiente Virtual de Aprendizagem, arquivo, o qual será encaminhado para correção de professores especialistas em BMG Canvas. O acadêmico receberá retorno com os apontamentos do professor e terá um prazo para fazer as devidas correções/adequações, se necessárias, e postará novamente, haverá nova correção e atribuição de nota final.

TCC II O TCC II é iniciado após o $1^{\circ}$ ano de curso, a cada UTA - Unidade Temática de Aprendizagem, que é composta de 4 disciplinas afins, com temas e conteúdo que guardam similaridade e proximidade. Em cada uma, o acadêmico deve elaborar um trabalho, o qual consiste em uma parte de um Plano de Negócios, assim, por exemplo, na UTA Colaboradores, que tem disciplinas voltadas à Gestão de Pessoas, o trabalho consiste na criação de uma estrutura de gestão de pessoas, devendo apresentar número de trabalhadores que a empresa modelada no BMG Canvas irá contratar, fazer descrição e análise dos principais cargos, apresentar salários e benefícios que serão oferecidos. A elaboração de cada tarefa está descrita em um documento denominado de Plano de Trabalho, onde se esclarece passo a passo qual tarefa o acadêmico tem de realizar em uma Planilha de Excel, com abas de cada atividade que deverá concluir. Ao final do quadrimestre o material produzido por meio da Planilha deverá ser postado e a nota atribuída pelo corretor, não haverá segunda postagem, nem tempo para fazer adequações e adaptações. Em cada uma das UTAs: Colaboradores, Logística, Operações, Estratégia, Marketing e Financeira haverá atividades a serem realizadas, descritas detalhadamente no Plano de Trabalho. Ao momento de realizar o TCC II, se o acadêmico fez todas as atividades da UTA anterior ele fará a compilação dos trabalhos realizados e relatórios produzidos e terá um Plano de Negócios completo. Então, para finalizar terá que fazer um relatório, analisando cada um dos trabalhos produzidos nas UTAs anteriores. O trabalho deverá ser postado no ambiente virtual de aprendizagem, que será corrigido pelo professor orientador e devolvido para ajustes e correções. $O$ estudante postará novamente e atribuído nota final. Para finalizar o projeto de TCC, o acadêmico agendará um horário no polo no qual ele estuda e será confrontado com uma banca examinadora, na apresentará o projeto de TCC. O tempo de apresentação será de 15 minutos, e a banca terá 20 minutos para apresentar as dúvidas e questionamentos.

\section{O TCC E AS COMPETENCIAS DO ADMINISTRADOR}

O projeto de TCC para o curso de Administração EAD vai ao encontro das competências apresentadas no PPC do curso. Bem como ao encontro das competências do ENADE e do CRA. No TCC I o graduando deve definir o seu negócio ao preencher uma tabela 
BMG CANVAS. Desta forma ele deve reconhecer e definir o problema, que é uma demanda não atendida no mercado, e uma oportunidade para o administrador, desta forma atende a primeira solicitação do DCN. Esta também vai ao encontro da primeira competência do ENADE, que é "reconhecer e delimitar problemas e oportunidades". No momento que o acadêmico determina um negócio, ele identifica uma oportunidade no mercado. E ao preencher a tabela BMG CANVAS responde as necessidades da estrutura da organização. E ainda, atende a demanda do CRA que apresenta a primeira competência como "identificar problemas, formular e implantar soluções". Nesta proposta, o graduando não somente identifica um problema, como também apresenta a solução, ao expor como a organização se relacionará com o mercado, quais são seus principais clientes, quem são seus parceiros, e sua fonte financeira.

Observa-se que o TCC I, apresentado pelo curso de Administração, vai ao encontro das competências de base estabelecidas pela DCN, pelo ENADE e pelo CRA. No TCC II é elaborado um plano de ação abordando as principais áreas da organização: Colaboradores, Logística, Operações, Estratégia, Marketing e Financeira. O objetivo é que o graduando visualize e estruture as diversas áreas da organização, como no exemplo citado da UTA Colaboradores, na qual é apresentado o número de colaboradores, salários, descrição da função. Em suma, é apresentado toda uma base, uma condição de como funcionará esse setor da organização. Ao estimular o acadêmico a pensar desta forma, o projeto atende a solicitação do ENADE nas seguintes demandas: Il-Propor e implementar, com efetividade, ações alinhadas às estratégias da organização; IV - Coordenar e integrar as diferentes áreas funcionais da organização.

Neste caso é solicitado ao acadêmico pensar de modo integrado a organização, que age de modo sistêmico entre todas as partes. $O$ acadêmico deve integrar as diferentes áreas da organização para que ela funcione como um todo. Ao desenvolver um plano de ação para cada área o acadêmico atende também a demanda da DCN com a seguinte competência: VI -desenvolver a capacidade de transferir conhecimentos da vida e da experiência cotidiana para o ambiente de trabalho e do seu campo de atuação, em diferentes modelos organizacionais, revelando-se profissional adaptável; E também: VII - desenvolver capacidade de elaborar, implementar e consolidar projetos em organizações.

Identificar e alocar recursos, pessoas e funções também é uma demanda do Enade, que é atendida no projeto, no momento que o acadêmico apresenta e define como será alocado dentro da organização as pessoas, o custo de cada uma delas e a função que cada uma irá desenvolver. Desenvolver raciocínio lógico, crítico e analítico para operar com valores e formulações matemáticas presentes nas relações formais e causais entre 
fenômenos produtivos, administrativos e de controle, bem assim expressando-se de modo crítico e criativo diante dos diferentes contextos organizacionais e sociais é a demanda IV do DCN. Está é contemplada quando o acadêmico pensa estrategicamente na UTA Financeira, onde elabora e apresenta um plano de ação, utiliza um raciocínio lógico com formulação de matemática, com análise de causa e efeito. Nesta UTA ele fará uma análise do mercado, com custos e uma projeção de futuro, que atende à demanda do CRA que é interpretar e analisar cenários. E sem esquecer, que permite monitorar resultados e avaliar desempenho, conforme a competência VII do Enade.

Ao estruturar um Plano de ação para cada área da organização, o acadêmico desenvolve raciocínio lógico, crítico e analítico sobre a realidade organizacional que atende a competência II do CRA. Bem como assume a responsabilidade do processo decisório nas ações de planejamento da organização que vai ao encontro da competência III do CRA. O objetivo dos órgãos reguladores, DNC, ENADE e CRA é garantir uma melhor qualidade ao formando do curso de Administração do país. As competências atendem uma demanda do mercado, que necessita de profissionais capacitados, aptos a identificar e resolver problemas, pensar estrategicamente, desenvolver raciocínio lógicos, propor e melhorias, promover a comunicação interna e externar, analisar resultados, encontrar solução aos novos desafios. Esses objetivos todos são abordados no projeto de TCC I e II. Oferecendo a sociedade um administrador mais competente. A desvantagem do modelo é que não permite desenvolver o capital humano, como liderança e trabalho em equipe. Também não é possível negociar e mediar. Competências essas que são limitadas no modelo de $E A D$, visto que o acadêmico realiza suas atividades a distância, no seu tempo e ritmo.

\section{CONSIDERAÇÕES FINAIS}

Que a educação à distância é uma realidade já consolidada no Brasil ninguém discute, mas o quanto ela consegue formar com qualidade seus alunos é um ponto que continua merecendo estudos e pesquisas. Neste artigo argumentamos que por meio do TCC é possível sim desenvolver as competências requeridas do Administrador, como está organizado e estruturado consegue contribuir para a formação das competências presentes nas DCN, o que é cobrado por meio do ENADE e aquelas listadas pelo CFC. Claro, que como é um projeto que está em seu início, alterações devem ser implementadas para aperfeiçoá-lo com vistas a melhorar sua estrutura e funcionamento, com isso, esperamos que consiga a cada nova turma que venha realizar seu Trabalho de Conclusão de Curso - TCC possa ter como resultado final as competências esperadas do Administrador desenvolvidas de forma sólida e que propicie ao profissional uma atuação que traga resultados à sua carreira e à empresa a qual estiver 
vinculada. Novos estudos devem ser conduzidos para se verificar em que grau essas competências são formadas e o quanto elas conseguem contribuir para uma atuação efetiva e produtiva, proporcionando resultados pelo Administrador.

\section{REFERÊNCIAS}

BENFATI, E. F. S. S.; STANO, R. C. M. T. Utilização da Tecnologia e Educação a Distância na Formação de Engenheiros de Produção - uma avaliação educacional. Revista Gestão e Produção, São Carlos, vol.17, no 2, p.433-446, 2010.

BRASIL. Decreto no 5.622, de 19 de dezembro de 2005. Regulamenta o art. 80 da Lei no 9.394, de 20 de dezembro de 1996, que estabelece as diretrizes e bases da educação nacional. Diário Oficial da União. Brasília, DF, 20 dez. 2005. Disponível em: https://www.planalto.gov.br/ccivil_03/_Ato2004-2006/2005/Decreto/D5622.htm. Acesso em: 28 abr. 2018.

CAVALCANTI, Vera Lucia, et al. Liderança e motivação, Rio de Janeiro: FGV, 2005.

FERREIRA, A.B.H. Novo Dicionário Aurélio. Rio de Janeiro: Nova Fronteira, 1995. $1499 \mathrm{p}$.

GOUVÊA, G. e OLIVEIRA, C. I. Educação a Distância na Formação de Professores: Viabilidades, potencialidades e limites. Rio de Janeiro: Vieira \& Lent, 2006.

KENSKI, V. M. Tecnologias e Ensino Presencial e a Distância. 9. ed. Campinas: Papirus, 2012.

MOORE, M.; KEARSLEY. Educação a Distância: uma visão integrada. São Paulo: Cengage Learning, 2008.

MORAN, J. Coleção Mídias Contemporâneas. Convergências Midiáticas, Educação e Cidadania: aproximações jovens. Vol. II Carlos Alberto de Souza e Ofelia Elisa Torres Morales (orgs.). Ponta Grossa: Foca Foto-PROEX/UEPG, 2015. Disponível em: http://www2.eca.usp.br/moran/wp-content/uploads/2013/12/mudando_moran.pdfAcesso em: 25 abr. 2016.

OSTERWALDER, A.; PIGNCUR, Y. Business Model Generation - Inovação em Modelos de Negócios: um manual para visionários, inovadores e revolucionários, Rio de Janeiro, RJ : Alta Books, 2011. 
PERRY, W.; RUMBLE, G. A short guide to distance education. Cambridge: International Extension College, 1997.

QUINN, Robert E. et al. Competências gerenciais: Princípios e aplicações. 3. ed. Rio de Janeiro: Elsevier, 2004.

SEVERINO, Antônio J. Metodologia do trabalho científico. 23. ed. ver. e atualizada. São Paulo: Cortez, 2007.

VASCONCELOS, Ce. dos S. Construção do conhecimento em sala de aula. 17. ed. São Paulo: Libertad, 2005. 